\title{
Using PVA, Methacrylate and Lauroyl Chitosan as Separator in Supercapacitors
}

\author{
M. A. Hashim ${ }^{1}$, Lawal Sa'adu ${ }^{1}$, Masbudi bin Baharuddin ${ }^{1} \&$ Karsono A. Dasuki ${ }^{1}$ \\ ${ }^{1}$ Faculty of Science and Technology, Universiti Sains Islam Malaysia (USIM), Malaysia \\ Correspondence: Lawal Sa'adu, Faculty of Science and Technology, Universiti Sains Islam Malaysia (USIM), \\ Bandar Baru Nilai, Negeri Sembilan 71800, Malaysia. E-mail: lawals2004@gmail.com
}

Received: September 16, 2013 Accepted: September 30, 2013 Online Published: November 11, 2013

doi:10.5539/jmsr.v3n1p25 URL: http://dx.doi.org/10.5539/jmsr.v3n1p25

\begin{abstract}
A separator is prepared from the resulting mixture of hybrid polymer electrolyte polyvinyl alcohol (PVA) (70\%) and Phosphoric acid $\left(\mathrm{H}_{3} \mathrm{PO}_{4}\right)(30 \%)$ immersed in the solution of the combination of polymethyl (methacrylate) and lauroyl chitosan (PLC), for supercapacitor application. The Electrochemical Impedance Spectroscopy (EIS) was conducted twice at normal temperature in an interval of Seven days with very high electrical conductivity of to be $6.42 \times 10^{-4} \mathrm{~S} \cdot \mathrm{cm}^{-1}$ and $1.84 \times 10^{-4} \mathrm{~S} \cdot \mathrm{cm}^{-1}$ within these intervals respectively and very low resistance. The supercapacitor was then fabricated using a Commercially Prepared Multi-walled Carbon Nanotube (CPMWCNT) which was sized to an area of $3.5 \mathrm{~cm}^{2}$ and assembled in an innovative supercapacitor tester. The result indicates a relatively high efficiency of about $90 \%$ and also exhibited long and excellent cycleability of life time $(>1000$ cycles) under different voltage windows.
\end{abstract}

Keywords: supercapacitor, Carbon Nanotube, charge-discharge, cycle-voltammetry

\section{Introduction}

Nowadays, pursue for energy sustainability have made electrochemical supercapacitors or ultracapacitors (Graeme, Gregory, \& Anthony, 2009; Inagakia, Konno, \& Tanaike, 2010; Jayalakshm, Venugopal, Raja, \& Rao, 2006; Rathod et al., 2009; Zhao et al., 2009) as devices of utmost importance due to their superior characteristics that are competitive to other charge storage devices. Such characteristics include; high power densities (Ganesh, Kalpana, \& Renganathan, 2008; Girija \& Sangaranarayanan, 2006; Ionica-Bousquet et al., 2011; Jampani, Manivannan, \& Kumta, 2010; Liu \& Pickup, 2008; Mastragostino \& Soavi, 2007; Orita, Kamijima, \& Yoshida, 2010; Yamada, Moriguchi, \& Kudo, 2008), and relatively high energy densities less than that of lithium ion batteries - (Inagakia \& Konnoa, 2010) and long cycle life (Ganesh, Kalpana, \& Renganathan, 2008; Graeme, Gregory, \& Anthony, 2009; Jampani, Manivannan, \& Kumta, 2010; Rathod et al., 2009; Zhao et al., 2009) and also broader range of working temperature (Lazzari, Soavi, \& Mastragostino, 2008), high coulombic efficiency (high reversibility), environmental friendliness (no heavy metals used) (Inagakia \& Konnoa, 2010; Zhao et al., 2009). More so, obtaining high capacitance in supercapacitor is attributed to having efficient electrolyte, likewise, utilization of high surface area electrode leads to high performance supercapacitors. These are always the two basic issues that current research focuses on. In this regards, the need to have a supercapacitor with aforementioned characteristics became inevitable (Lewandowski \& Galinski, 2007).

Currently in the market, Nafion membrane that is composed of a hydrophobic Teflon backbone and side chains and hydrophilic sulfonic acid $\left(-\mathrm{SO}_{3} \mathrm{H}\right)$ groups has been a common separator used in supercapacitors. Nafion membrane had a setback due to its expensiveness and most importantly limited raw material. Eggshell membrane have also been tipped to be one of the promising materials, but its extravagance nature of usage and costly nature need to be taken into consideration (Lewandowski \& Galinski, 2007).

Polyvinyl alcohol and Lauroyl Chitosan were both considered to be of wonderful materials, with the former being very good mechanical strength and cost effective (Mastragostino \& Soavi, 2007) and later having the high levels of mechanical strength and ionic liquid retention required in EDLC cells (Liu \& Pickup, 2008).

This paper is aimed at introducing yet another easy but effective and cost-manageable method of fabricating an optimized supercapacitor that has been incorporated with a multi-walled commercial carbon nanotube and Hybrid Solid Polymer Electrolyte (HSPE). 


\section{Experimental}

\subsection{Electrolytic Material}

Hybrid solid polymer electrolyte was prepared from a $70 \%$ of polyvinyl alcohol (PVA) and 30\% of Phosphoric acid $\left(\mathrm{H}_{3} \mathrm{PO}_{4}\right)$ with cellulose filter paper immersed in to it. The immersed cellulose paper was then dried in a plastic Petri dish. On the other hand, a separate solution consisting of $0.6 \mathrm{~g}$ of polymethyl (methacrylate) and 0.4 $\mathrm{g}$ of lauroyl chitosan (PLC) was prepared and mixture together, and the former was then diluted to a $100 \mathrm{ml}$ of Tetrahydrofuran (THF) before both are being measured and transferred to five (5) schott bottles. A 30\% Lithium Triflate was added to each of the solution in the bottles. The dried hybrid polymer was then immersed in the solution of PLC and then used as an optimised hybrid polymer electrolyte.

\subsection{Electrode Materials and Cell Assembly}

Commercially Prepared Carbon Nanotube (CPMWCNT) with the following specifications; an outer diameter of $8-15 \mathrm{~nm}$, length of $0.5-2 \mathrm{~m}$, purity and Ash are both $>95 \mathrm{wt} \%$, and $<1.5 \mathrm{wt} \%$ respectively, Surface area of $>$ $233 \mathrm{~m}^{2} / \mathrm{g}$ and Conductivity of $>10^{2} \mathrm{~s} / \mathrm{cm}$ was obtained for this cell assembly.

Majority of the electrochemical double layer experiments were made using two-electrode Swagelok cells (Ionica-Bousquet et al., 2011). But in this case, the separator with already prepared electrolyte and an area of 3.5 $\mathrm{cm}^{2}$ was selected for this purpose. A $0.15 \mathrm{~g}$ of the CPMWCNT was sprinkled on both sides of the separator before it was finally assembled in an innovative supercapacitor tester. With the help of aluminium foil, both positive and negative sides of the supercapacitor were initiated, and then the supercacitor was ready for characterization.

\section{Result and Discussion}

\subsection{Material Characterization}

The thermogravimetric analysis (TGA) was carried out in the scale-range of $50{ }^{\circ} \mathrm{C}$ to $800{ }^{\circ} \mathrm{C}$ under nitrogen gas $\left(\mathrm{N}_{2}\right)$ flow at a heating rate of $10{ }^{\circ} \mathrm{C} \mathrm{min}^{-1}$ on a METTLER, STAR ${ }^{\mathrm{e}} \mathrm{SW} 10.00$ thermal analyzer. This is pertinent, since the carbon nanotube was obtained commercially, thus verifying its thermal stability will certainly give a clue as to its capability in terms of thermal stability. Interestingly from Figure 1, the commercial CNT shows a thermal stability of up to $550^{\circ} \mathrm{C}$ and with presence of huge residue at $87.7607 \%(20.2807 \mathrm{mg}$ of the $23.1091 \mathrm{mg})$ at a temperature of $762.86^{\circ} \mathrm{C}$.

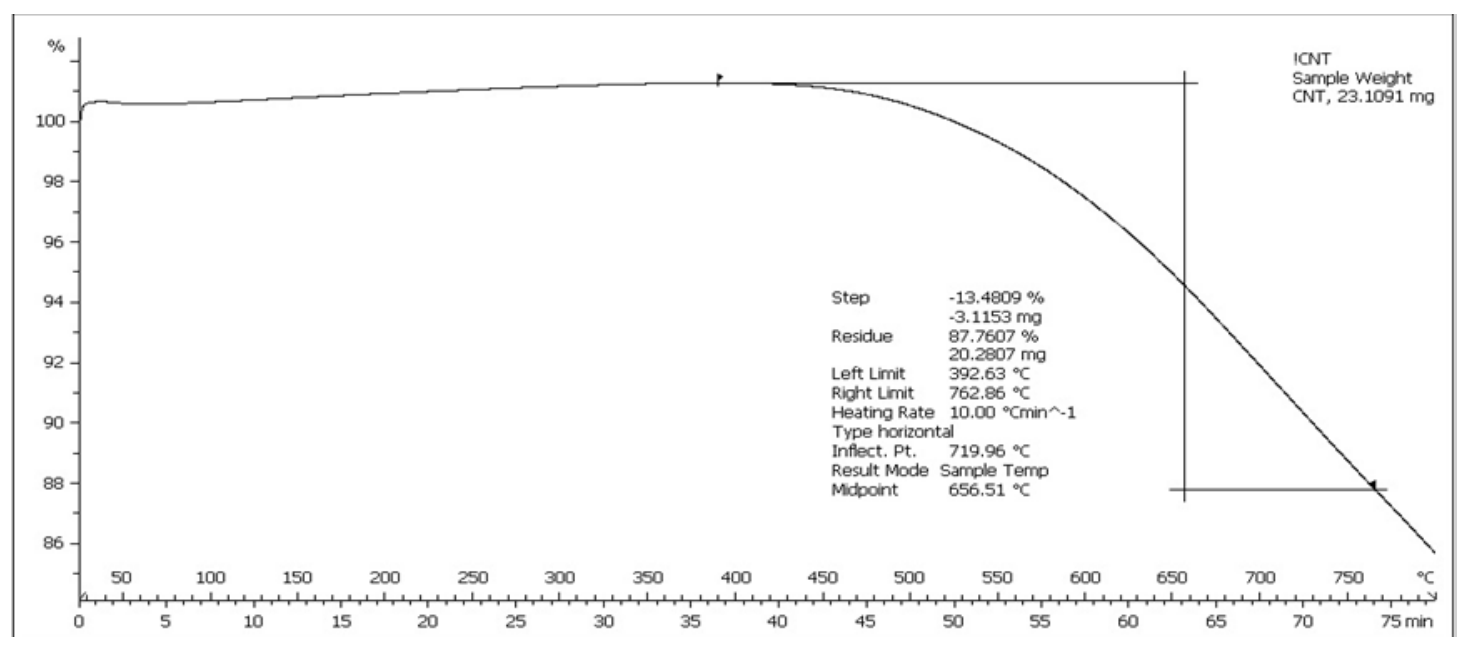

Figure 1. TGA thermodiagram of the commercial multiwalled-carbon nanotube

\subsection{Electrolytic Performance}

The impedance spectroscopy measurement was carried out in order to determine the conductivity and frequency behaviour. So, in this case the impedance was measured twice at room temperature in an interval of 168 hours using the same machine and technique used by (Ahmad Khiar \& Arof, 2010) so as to determine the rate of stability or otherwise of the electrolytic material. Using the popular equation; 


$$
\sigma=\frac{l}{R_{b} A}
$$

Where $R_{b}$ is the bulk resistance and $\sigma, l, A$ are conductivity, thickness and area of the samples respectively. In this regard, the bulk resistance, $R_{b}$ of the sample was tested twice - on the first sample test and after 168 hours (1 week) - and both were found to be $2.6 \Omega$ and $9.06 \Omega$ respectively, while their conductivity $\sigma$ were calculated to be $6.42 \times 10^{-4} \mathrm{~S} \cdot \mathrm{cm}^{-1}$ and $1.84 \times 10^{-4} \mathrm{~S} \cdot \mathrm{cm}^{-1}$ respectively. This clearly shows (as in Figure 2) a good stability of the electrolyte film mechanically even when it was kept for seven days.
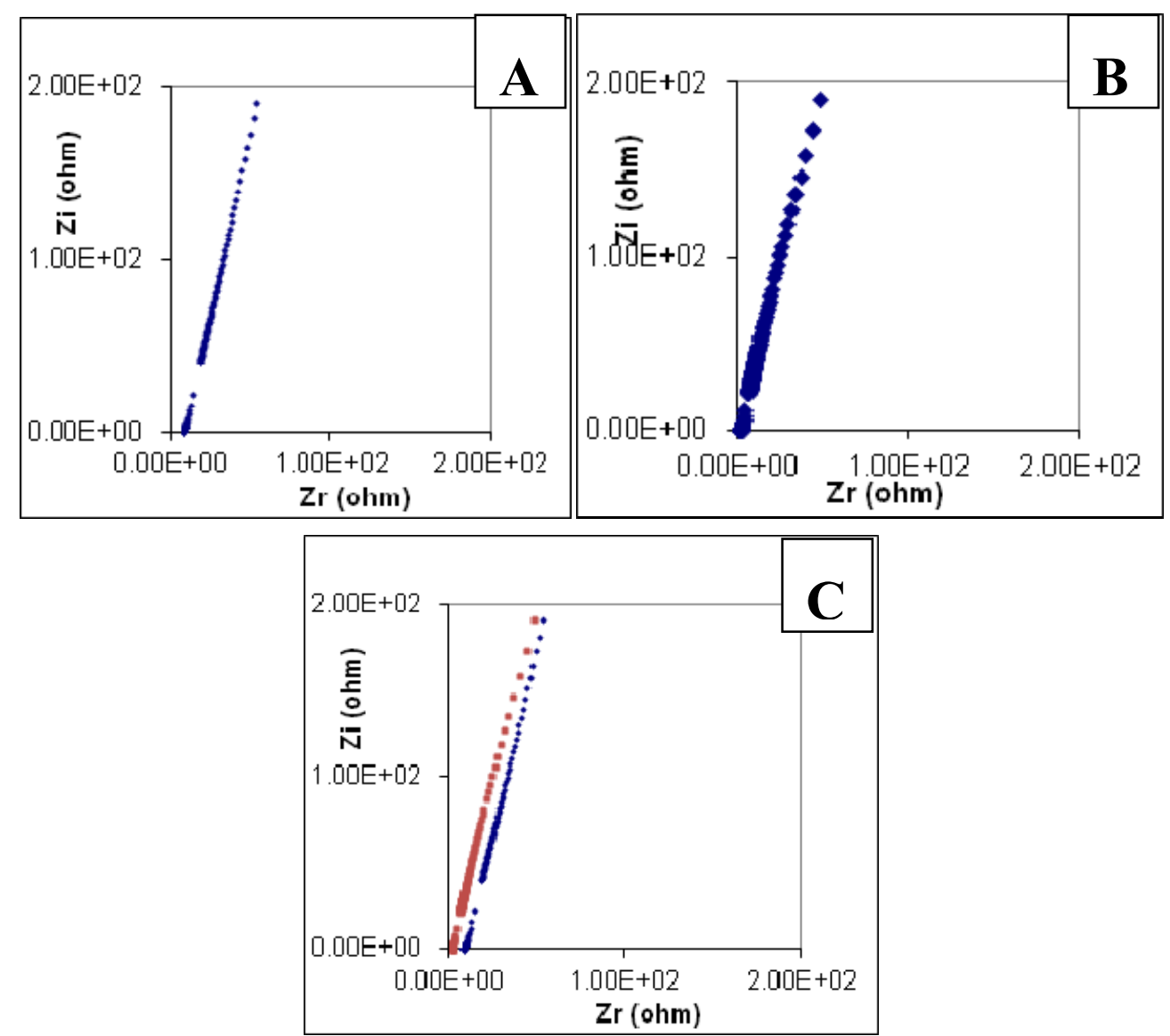

Figure 2. Impedance plots of the electrolyte sample at the first day (A), a week after (B) and a combine A and B

\subsection{Supercapacitor Performance}

The EDLC cell after being assembled was tested using the commonly used Multichannel charge-discharge (MCCD) and Multichannel charge-discharged machines normally used for the analysis of the supercapacitor. This testing technique has been used by (Hashim, Lawal, \& Karsono, 2012).

Using Gamry instruments with a scan rate of $10 \mathrm{~mA}$, the cycleability of the supercapacitor appeared to be good, even though, the maximum current was only set to $3.0 \mathrm{~mA}$ and $0.8 \mathrm{~V}$ voltage window as shown in Figure 3A.

Multichannel charge-discharge (MCCD) machine was used to analyze and calculate the capacitance of the 3.5 $\mathrm{cm}^{2}$ supercapacitor. As shown in Figure 3B, the inverse V-shape of the curve with less internal resistance and voltage increment with time, indicates the efficiency of the supercapacitor. Specific capacitance, energy of the capacitor and supercapacitor's power density were all calculated to be $33.3 \mathrm{~F} / \mathrm{g}, 16.7 \mathrm{~J} / \mathrm{g}$ and $8.3 \mathrm{~J} / \mathrm{g} / \mathrm{s}$ respectively, with the efficiency of more than $90 \%$. 


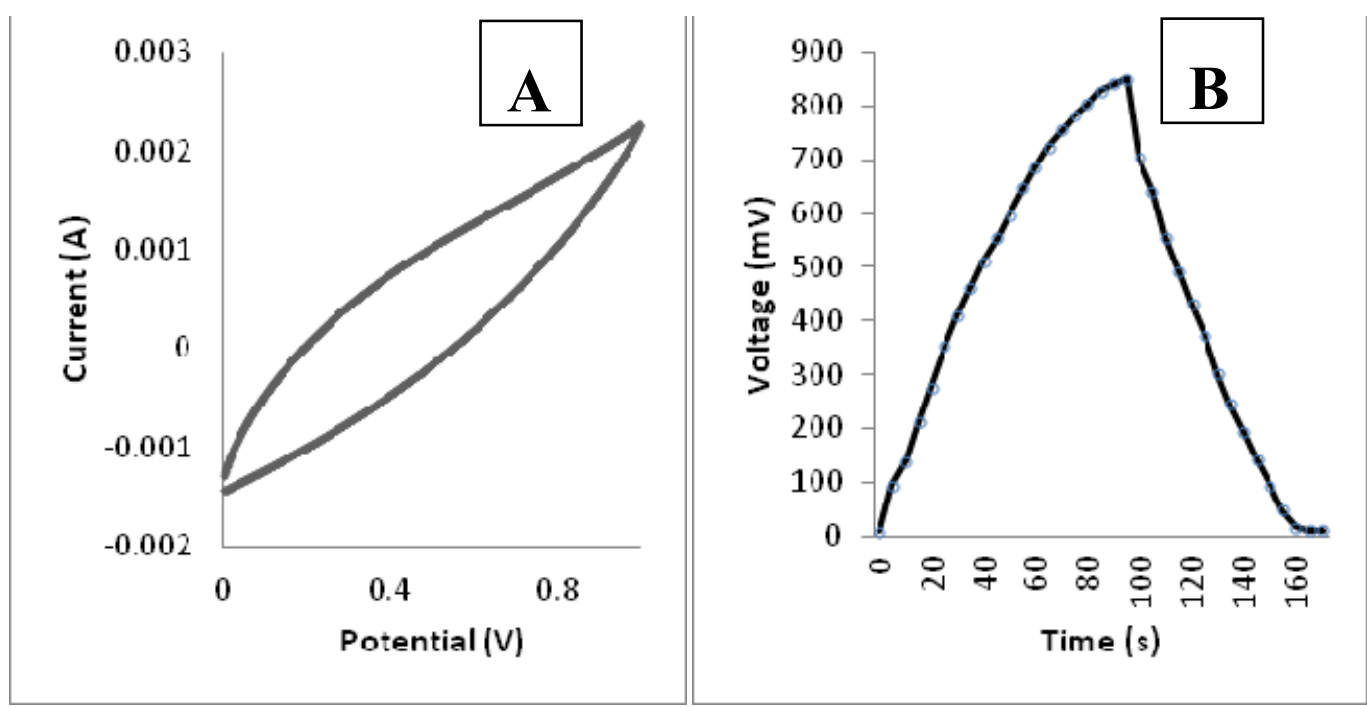

Figure 3. (A) cyclic voltammetry using Gamry instrument software at maximum current of $0.3 \mathrm{~mA}$ and scan rate of $10 \mathrm{mV} / \mathrm{s}, 1$ cycle and voltage window of $1 \mathrm{~V}$, (B) Charge-discharge at voltage window of $0.9 \mathrm{~V}$ for 160 seconds at 1 cycle

\section{Conclusion}

In this work, we explored the noble of polyvinyl alcohol (PVA) and Phosphoric acid $\left(\mathrm{H}_{3} \mathrm{PO}_{4}\right)$ with cellulose filter paper and another separate solution of the combination of polymethyl (methacrylate) and lauroyl chitosan (PLC) and commercially prepared carbon nanotube (CPMWCNT) used as an electrolyte and electrode respectively for the fabrication of Supercapacitor. The results discussed concur, suggesting that, the electrolyte performance was perfect due to high conductivity recorded when tested for the electrochemical impedance spectroscopy (EIS). The commercial carbon nanotube was shown to have thermal stability capable of being used as an electrode material for the purpose of this experiment. The overall formation gave balanced results for the supercapacitor as far its efficiency, specific capacitance, and energy and power densities of the capacitance. High capacity of the supercapacitor can be achieved by enhancing the quality of the polymer electrolyte and reducing the thickness of the electrode.

\section{Acknowledgements}

The corresponding author wish to acknowledge the assistance and contributions of management of Faculty of Science and Technology USIM under which ERGS grant (USIM/ERGS-FST-52-50111) has been provided for the purpose of this research.

\section{References}

Ahmad Khiar, A. S., \& Arof, A. K. (2010). Conductivity Studies of Starched-based polymer electrolytes. Ionics, 16, 123-129.

Ganesh, A., Kalpana, D., \& Renganathan, N. G. (2008). Acrylamide based proton conducting polymer gel electrolyte for elec-tric double layer capacitors. Ionics, 14, 339-343.

Girija, T. C., \& Sangaranarayanan, M. V. (2006). Analysis of polya-niline-based nickel electrodes for electrochemical super-capacitors. Journal of Power Sources, 156, 705-711. http://dx.doi.org/10.1016/j.jpowsour.2005.05.051

Graeme, A. S., Gregory, J. W., \& Anthony, G. P. (2009). Mathematical functions for optimisation of conducting poly-mer/activated carbon asymmetric supercapacitors. Journal of Power Sources, 186, 216-223. http://dx.doi.org/10.1016/j.jpowsour.2008.09.085

Hashim, M. A., Lawal, Sa'adu \& Karsono, A. D. (2012). Supercapacitors based on activated carbon and polymer electrolyte. International Journal of Sustainable Energy and Environmental Research, 1, 1-6.

Inagaki, M., Konno, H., \& Tanaike, O. (2010). Carbon materials for electrochemical capacitors. Journal of Power Source, 195, 7880-7903. http://dx.doi.org/10.1016/j.jpowsour.2010.06.036 
Ionica-Bousquet, C. M., Munoz-Rojasa, D., Casteel, W. J. J., Pearlstein, R. M., Girish, G. K., Pez, G. P., \& Palacin, M. R. (2011). Polyfluorinated boron cluster based salts: A new electrolyte for application in nonaqueous asymmetric AC/Li $\mathrm{Li}_{5} \mathrm{O}_{12}$ supercapacitors. Journal of Power Sources, 196, 1626-1631. http://dx.doi.org/10.1016/j.jpowsour.2010.08.082

Jampani, A. P., Manivannan, P., \& Kumta, N. (2010). Advancing the Supercapacitor and Technology Frontier for improving power quality. Electrochemical Society Interface, 57-56.

Jayalakshmi, M., Venugopal, N. K., Raja, P., \& Rao, M. M. (2006). Nano $\mathrm{SnO}_{2}-\mathrm{Al}_{2} \mathrm{O}_{3}$ mixed oxide and $\mathrm{SnO}_{2}-\mathrm{Al}_{2} \mathrm{O}_{3}$-carbon composite oxides as new and novel electrodes for supercapacitor applications. Journal of Power Sources, 158, 1538-1543. http://dx.doi.org/10.1016/j.jpowsour.2005.10.091

Lazzari, M., Soavi, F., \& Mastragostino, M. (2008). High voltage, asymmetric EDLCs based on xerogel carbon and hydro-phobic IL electrolytes. Journal of Power Sources, 178, 490-496. http://dx.doi.org/10.1016/j.jpowsour.2007.12.029

Lewandowski, A., \& Galinski, M. (2007). Practical and theoretical limits for electrochemical double-layer capacitors. Journal of Power Sources, 173, 822-828. http://dx.doi.org/10.1016/j.jpowsour.2007.05.062

Liu, X., \& Pickup, P. G. (2008). Ru oxide supercapacitors with high loadings and high power and energy densities. Journal of Power Sources, 176, 410-416. http://dx.doi.org/10.1016/j.jpowsour.2007.10.076

Mastragostino, M., \& Soavi, F. (2007). Strategies for high-performance supercapacitors for HEV. Journal of Power Sources, 174, 89-93. http://dx.doi.org/10.1016/j.jpowsour.2007.06.009

Orita, A., Kamijima, K., \& Yoshida, M. (2010). Allyl-functionalized ionic liquids as electrolytes for electric double-layer ca-pacitors. Journal of Power Sources, 195, 7471-7479. http://dx.doi.org/10.1016/j.jpowsour.2010.05.066

Rathod, D., Vijay, M., Islam, N., Kannan, R., Kharul U., Sreekumar, K., \& Vijayamohanan, P. (2009). Design of an "all solid-state" supercapacitor based on phosphoric acid doped polybenzimidazole (PBI) electrolyte. $J$. Appl. Electrochem, 39, 1097-1103.

Yamada, H., Moriguchi, I., \& Kudo, T. (2008). Electric double layer capacitance on hierarchical porous carbons in an organic electrolyte. Journal of Power Sources, 175, 651-656. http://dx.doi.org/10.1016/j.jpowsour.2007.09.037

Zhao, X., Tian, H., Zhu, M., Tian, K., Wang, J. J., Kang, F., \& Outlaw, R. A. (2009). Carbon nanosheets as the electrode material in supercapacitors. Journal of Power Sources, 94, 1208-1212. http://dx.doi.org/10.1016/j.jpowsour.2009.06.004

\section{Copyrights}

Copyright for this article is retained by the author(s), with first publication rights granted to the journal.

This is an open-access article distributed under the terms and conditions of the Creative Commons Attribution license (http://creativecommons.org/licenses/by/3.0/). 